\title{
Regulation of NMDA Receptor Activity by F-Actin and Myosin Light Chain Kinase
}

\author{
Saobo Lei, ${ }^{1}$ Elzbieta Czerwinska, ${ }^{1}$ Waldemar Czerwinski, ${ }^{1}$ Michael P. Walsh, ${ }^{2}$ and John F. MacDonald ${ }^{1}$ \\ ${ }^{1}$ Canadian Institutes of Health Research Group "The Synapse," Departments of Physiology and Pharmacology, University \\ of Toronto, Toronto M5S 1A8, Canada, and ${ }^{2}$ Canadian Institutes of Health Research Group in Regulation of Vascular \\ Contractility and The Smooth Muscle Research Group, Department of Biochemistry and Molecular Biology, University of \\ Calgary, Calgary T2N 4N1, Canada
}

The postsynaptic density (PSD) at excitatory dendritic synapses comprises a protein complex of glutamate receptors, scaffolding elements, and signaling enzymes. For example, NMDA receptors (NMDARs) are linked to several proteins in the PSD, such as PSD-95, and are also tethered via binding proteins such as $\alpha$-actinin directly to filamentous actin of the cytoskeleton. Depolymerization of the cytoskeleton modulates the activity of NMDARs, and, in turn, strong activation of NMDARs can trigger depolymerization of actin. Myosin, the motor protein of muscular contraction and nonmuscle motility, is also associated with NMDARs and the PSD. We show here that constitutively active myosin light chain kinase (MLCK) enhances NMDAR-mediated whole-cell and synaptic currents in acutely isolated CA1 pyramidal and cultured hippocampal neurons, whereas inhibitors of MLCK depress these currents.

Contraction of smooth muscle cells is primarily mediated via $\mathrm{Ca}^{2+}$-calmodulin (CaM)-dependent stimulation of myosin light chain kinase (MLCK) and the subsequent phosphorylation of myosin light chains (MLCs). Increased myosin-ATPase activity then drives the cycling of myosin cross bridges along actin filaments resulting in contraction (Allen and Walsh, 1994). MLCK is not restricted to smooth muscle and regulates various functions related to motility in nonmuscle cells, including neurons. For example, MLCK increases mobilization of synaptic vesicles (Ryan, 1999), facilitates neurotransmitter release (Mochida et al., 1994), and modulates growth cone migration and neurite elongation (Jian et al., 1996; Ruchhoeft and Harris, 1997). MLCK is a highly substrate-specific kinase; the only known physiological substrate of MLCK is myosin II, specifically the regulatory light chain subunits (Kamm and Stull, 2001)

Filamentous actin is concentrated in the postsynaptic dendritic spines of excitatory glutamatergic synapses of hippocampal neurons (Allison et al., 1998), and synaptic plasticity has been linked to dynamic changes in the number and shape of these spines (Matus, 2000; Matus et al., 2000). Although actin provides struc-

\footnotetext{
Received June 15, 2001; revised Aug. 10, 2001; accepted Aug. 14, 2001.

This work was supported by grants to J.F.M. and M.P.W. from the Canadian Institutes of Health Research and a Neurotrauma Foundation of Ontario (NFO) grant to J.F.M. S.L. is a Fellow of the NFO. M.P.W. is an Alberta Heritage Foundation for Medical Research Medical Scientist and recipient of a Canada Research Chair in Biochemistry.

Correspondence should be addressed Dr. S. Lei, c/o J. F. MacDonald, Department of Physiology, Medical Sciences Building, University of Toronto, Toronto M5S 1A8, Canada. E-mail j.macdonald@utoronto.ca.

Copyright (ㄷ) 2001 Society for Neuroscience $\quad 0270-6474 / 01 / 218464-09 \$ 15.00 / 0$
}

This MLCK-dependent regulation was observed in cellattached patches but was lost after excision to inside-out patches. Furthermore, the enhancement induced by constitutively active MLCK and the depression of MLCK inhibitors were eliminated after depolymerization of the cytoskeleton. NMDARs and MLCK did not colocalize in clusters on the dendrites of cultured hippocampal neurons, further indicating that the effects of MLCK are mediated indirectly via actomyosin. Our results suggest that MLCK enhances actomyosin contractility to either increase the membrane tension on NMDARs or to alter physical relationships between the actin cytoskeleton and the linker proteins of NMDARs.

Key words: NMDA receptors; myosin light chain kinase; actin; glutamate receptors; cytoskeleton; excitatory synaptic currents

tural stability, it continuously undergoes dynamic remodeling (Fischer et al., 1998, 2000; Matus, 2000; Matus et al., 2000). The motility of dendritic spines and filopodia is regulated by activation of postsynaptic AMPA receptors (AMPARs) and NMDA receptors (NMDARs) (Van Rossum and Hanisch, 1999; Jontes and Smith, 2000), and these receptors bind to anchoring proteins in the postsynaptic density (PSD) (Sheng and Pak, 2000). However, NMDARs are intimately associated with the cytoskeleton via protein-protein interactions with neurofilaments (Ehlers et al., 1998), microtubules (Van Rossum et al., 1999), and actin filaments (Wyszynski et al., 1997; Wechsler and Teichberg, 1998; Krupp et al., 1999). Indeed, actin is coupled directly to NR1 and NR2 subunits of NMDARs via the actin binding proteins $\alpha$-actinin2 (Wyszynski et al., 1997; Krupp et al., 1999) and spectrin (Wechsler and Teichberg, 1998), respectively. In addition to being physically associated with the cytoskeleton, the activity of NMDARs is also dependent on the integrity of the actin cytoskeleton (Rosenmund and Westbrook, 1993a). Strong activation of NMDARs results in influx of $\mathrm{Ca}^{2+}$ sufficient to depolymerize actin and causes an irreversible downregulation of NMDA channel activity (Rosenmund and Westbrook, 1993b). In turn, depolymerization of the cytoskeleton is associated with a selective depression of NMDAR-mediated synaptic transmission (Sattler et al., 2000), altered numbers and distributions of glutamate receptors (Allison et al., 1998), and enhanced internalization of AMPARs (Zhou et al., 2001).

We investigated the potential MLCK-dependent regulation of NMDAR function in hippocampal neurons. Our rationale for this study is based on observations that (1) NMDARs are phys- 
ically and functionally associated with the actin cytoskeleton via $\alpha$-actinin and spectrin (Ehlers et al., 1996; Wechsler and Teichberg, 1998; Krupp et al., 1999), (2) NMDARs, $\alpha$-actinin, actin, spectrin, and myosin are all constituents of the PSD (Walsh and Kuruc, 1992; Kennedy, 1997; Husi et al., 2000; Naisbitt et al., 2000), and (3) MLCK is expressed in human hippocampal neurons (Potier et al., 1995). Our results demonstrate that MLCK regulates NMDA channel activity via the linkages between the actin cytoskeleton and NMDARs.

\section{MATERIALS AND METHODS}

Preparation of acutely isolated hippocampal CA1 neurons. CA1 hippocampal pyramidal neurons were acutely isolated using modified procedures of Wang and MacDonald (1995). Briefly, Wistar rats 2-3 weeks old were decapitated via a guillotine after halothane anesthesia. Hippocampi were rapidly removed and placed in a culture plate containing cold, oxygenated external solution consisting of (in $\mathrm{mm}$ ): $140 \mathrm{NaCl}, 1.3 \mathrm{CaCl}_{2}, 5.4$ $\mathrm{KCl}, 25 \mathrm{HEPES}, 33$ glucose, $1 \mathrm{MgCl}_{2}$, and 0.0003 tetrodotoxin, $\mathrm{pH} 7.4$ (osmolarity, 320-335 mOsm/1). Hippocampi were cut by hand with a razor blade into $300-500 \mu \mathrm{m}$ slices. Slices were then digested at room temperature $\left(20-22^{\circ} \mathrm{C}\right)$ in external solution containing $5 \mathrm{mg} / \mathrm{ml}$ papaya latex (Sigma, St. Louis, MO). This incubation medium was stirred with pure oxygen blown in at the bottom of the container. After $30 \mathrm{~min}$ of enzymatic digestion, the slices were rinsed three times with external solution. Slices were maintained in external solution bubbled with oxygen and could be used for periods of up to $8-10 \mathrm{hr}$.

The CA1 region of each slice was microdissected with a scalpel, isolated under a phase-contrast microscope, and then triturated with a fire-polished glass pipette. Data were obtained only from large pyramidal cells that were phase-bright, clearly outlined, and lacked signs of swelling or damage.

Whole-cell patch-clamp recordings. Whole-cell recordings were performed with an Axopatch-1B amplifier (Axon Instruments, Foster City, CA) in the voltage-clamp mode. Recording electrodes, with resistances of 3-5 $\mathrm{M} \Omega$, were constructed from thin-walled borosilicate glass $(1.5 \mathrm{~mm}$ diameter; World Precision Instruments, Sarasota, FL) using a two-stage puller (PP83; Narishige, Tokyo, Japan). Data were digitized, filtered (2 $\mathrm{kHz}$ ), and acquired on-line using the programs of pClamp 6 (Axon Instruments). Unless stated otherwise, the internal solution for the recording electrodes consisted of the following (in $\mathrm{mM}$ ): $70 \mathrm{Cs}$ methylsulphonate, $70 \mathrm{CsF}, 35 \mathrm{CsOH}, 10 \mathrm{HEPES}, 2 \mathrm{MgCl}_{2}$, 2 tetraethylammonium, 1.1 EGTA, 0.25 $\mathrm{CaCl}_{2}$, and $4 \mathrm{Na}_{2} \mathrm{ATP}, \mathrm{pH} 7.3$ (osmolarity, 300 $\mathrm{mOsm} / \mathrm{l}$ ). The bathing solution for the recordings was the same as described above. A multibarreled perfusion system was used to achieve exchange of solutions ( $\tau$ of exchange, $\sim 2 \mathrm{msec}$ ).

NMDA $(50 \mu \mathrm{M})$ and glycine $(3 \mu \mathrm{M})$ were applied to neurons via one barrel for $2 \mathrm{sec}$, unless otherwise stated, to evoke NMDAR-mediated currents. The holding potential was set at $-60 \mathrm{mV}$. To study $\mathrm{Ca}^{2+}$-dependent inactivation, the extracellular concentrations of $\mathrm{Ca}^{2+}$, NMDA, and glycine were changed to $1.8 \mathrm{mM}, 20 \mu \mathrm{M}$, and $10 \mu \mathrm{M}$, respectively (Legendre et al., 1993; Zhang et al., 1998). Drugs were diluted in the external solution to the required concentrations and applied to the neurons via the control barrel unless otherwise stated. 1-(5-Iodonaphthalene1-sulfonyl)-1H-hexahydro-1,4-diazepine $\cdot \mathrm{HCl}(\mathrm{ML}-7)$ and 1-(5-chloronaphthalene-1-sulfonyl)-1H-hexahydro-1,4-diazepine $\cdot \mathrm{HCl}$ (ML-9) were obtained from Biomol (Plymouth Meeting, PA) and prepared as $100 \mathrm{~mm}$ stock solutions in DMSO. The final concentration of DMSO never exceeded $0.05 \%$, and this concentration of DMSO did not affect NMDA currents.

Low-density cultures of hippocampal neurons. Low-density hippocampal neuronal cultures were prepared from embryonic Swiss mice at day 17-19 of gestation (Sattler et al., 1999). Cells were plated on poly-Dlysine (Sigma)-coated glass coverslips at a density of 3000 cells $/ \mathrm{cm}^{2}$. Plating medium consisted of minimum essential medium-Earle's salt supplemented with $10 \%$ heat-inactivated horse serum, $10 \%$ fetal bovine serum, $31.6 \mathrm{~mm} \mathrm{NaHCO}{ }_{3}, 31 \mathrm{~mm}$ glucose, and $8 \mu \mathrm{g} / \mathrm{ml}$ insulin. The cultures were maintained at $37^{\circ} \mathrm{C}$ in a humidified $5 \% \mathrm{CO}_{2}$ atmosphere. After $24 \mathrm{hr}$ in culture, MEM was exchanged to Neurobasal MEM with B-27 supplement (Life Technologies, Gaithersburg, MD), and $10 \mu \mathrm{M}$ 5 -fluoro-2'-deoxyuridine solution was added to stop growth of nonneuronal cells. Cells were fed every other day with fresh serum-free medium and used at $14 \mathrm{~d}$ in vitro.

Immunostaining of cultured hippocampal neurons. Cultures were fixed in ice-cold 4\% paraformaldehyde in PBS for $20 \mathrm{~min}$, permeabilized with
$0.1 \%$ Triton X-100 for $0.5 \mathrm{hr}$, and blocked with $4 \%$ BSA for $1 \mathrm{hr}$. Cells were washed after each step with PBS and incubated with rabbit polyclonal antibodies to MLCK (Paul et al., 1995) in 2\% BSA, 0.5\% Triton $\mathrm{X}-100$, and PBS $(1: 700)$ overnight at $4^{\circ} \mathrm{C}$. Cultures were washed, blocked as the day before, and incubated with purified mouse antibodies to NMDAR1 (PharMingen, San Diego, CA) in 2\% BSA, 0.5\% Triton $\mathrm{X}-100$, and PBS $(1: 400)$ overnight at $4^{\circ} \mathrm{C}$. The cultures were then washed with PBS and incubated with secondary antibodies for $1.5 \mathrm{hr}$ at room temperature using donkey anti-rabbit IgG conjugated to $\mathrm{Cy} 3$ (red fluorescence) and donkey anti-mouse $\operatorname{IgG}$ conjugated to FITC (green fluorescence) (Jackson ImmunoResearch, West Grove, PA). Coverslips were mounted with antifade mounting medium and were viewed on an Olympus Optical (Tokyo, Japan) $(1 \times 70)$ inverted microscope equipped with Delta Vision hardware (Applied Precision, Issaquah, WA) and software for wide-field deconvolution microscopy.

Single-channel recordings. Single-channel activity was recorded from cultured mouse hippocampal neurons using the cell-attached or insideout patch configurations. After coating with Sylgard, the electrodes were fire-polished and filled with the standard external solution containing NMDA $(10 \mu \mathrm{M})$ and glycine $(3 \mu \mathrm{M})$. For cell-attached patches, cells were perfused with external solution. ML-7 (10 $\mu \mathrm{M})$ was applied to the cells via the perfusion barrel. The holding potential of patches was usually 0 $\mathrm{mV}$, but various potentials were used when acquiring data to calculate the single-channel conductance. For inside-out patch recordings, the patches were excised and bathed in a solution containing (in $\mathrm{mM}$ ): 120 $\mathrm{CsCl}, 35 \mathrm{CsOH}, 10 \mathrm{HEPES}, 2 \mathrm{MgCl}_{2}, 1$ EGTA, $0.5 \mathrm{CaCl}_{2}$, 2 tetraethylammonium, and $4 \mathrm{Na}_{2} \mathrm{ATP}$, pH 7.3 (osmolarity, $300 \mathrm{mOsm} / \mathrm{l}$ ). AV25 (AKKLAKDRMKK YMARRKLQKAGHAV) $(100 \mu \mathrm{M})$ or constitutively active MLCK (50 nM) was dissolved in this solution and applied to the cytoplasmic face of the patch. The holding potential was set at +60 $\mathrm{mV}$ for inside-out patches, except when data were acquired for the computation of single-channel conductances. Under these recording conditions, the detected single-channel currents were NMDA currents ( $\mathrm{Lu}$ et al., 1998; Lei et al., 1999).

Single-channel events were first recorded on videotape using a digital data recorder (VR-10; InstruTech, Mineola, NY) and later played back and acquired using pClamp 6 programs (Axon Instruments). Singlechannel currents were sampled at $5 \mathrm{kHz}$ and filtered at $3 \mathrm{kHz}$. Only patches with stable basal activities were analyzed to ensure that the changes in activity were not attributable to "rundown" or random fluctuations. Probability of opening, open times, and shut times were determined off-line using the $50 \%$ crossing thresholds method. Slope conductance was computed by linearly fitting the amplitudes recorded at different holding potentials. Analysis of dwell-time distributions was performed using the sum of multiple exponentials and the LevenbergMarquard least-squares method. Open dwell-time histograms were best fit with two to three components, and closed dwell-time histograms were best fit with four to five components. Adequacy of the number of components fitting the histograms was determined using the $F$ statistics test. For a better comparison, the mean open or closed dwell time was calculated as the weighted dwell time.

Miniature synaptic currents. Miniature EPSCs (mEPSCs) were recorded from 12-17 d cultured mouse hippocampal neurons. Detailed methods have been described previously (Lei et al., 1999). Briefly, spontaneous mEPSCs were recorded immediately after formation of the whole-cell patch configuration and continuously monitored for 30-60 min. Miniature EPSCs were filtered at $2 \mathrm{kHz}$ and acquired with an event detection program (SCAN; Strathclyde software, courtesy of Dr. J. Dempster, Department of Physiology and Pharmacology, University of Strathelyde, Glasgow, UK). For detection, the trigger level was set approximately three times higher than the baseline noise. False events were eliminated by subsequent inspection of the raw data. Cultured neurons were bathed in the external solution supplemented with $0.5 \mu \mathrm{M}$ tetrodotoxin, $1 \mu \mathrm{M}$ strychnine, $10 \mu \mathrm{M}$ bicuculline methiodide, and $3 \mu \mathrm{M}$ glycine. The spontaneous responses recorded in this solution were composite mEPSCs mediated by both NMDARs and AMPARs. For each neuron, 100-200 individual events were recorded and averaged at different times after formation of the whole-cell configuration. Miniature EPSCs mediated by AMPARs were detected by including 5-aminophosphonovaleric acid (AP-5) $(50 \mu \mathrm{M})$ in the bathing solution. Subtracting averaged AMPAR components from the averaged mEPSCs mediated by both NMDARs and AMPARs provided a measurement of the component of mEPSCs mediated by NMDARs ( $\left.\mathrm{mEPSC}_{\mathrm{NMDA}}\right)$.

Chemicals and reagents. The synthesis and preparation of the MLCK inhibitor peptide AV25 and constitutively active MLCK have been de- 

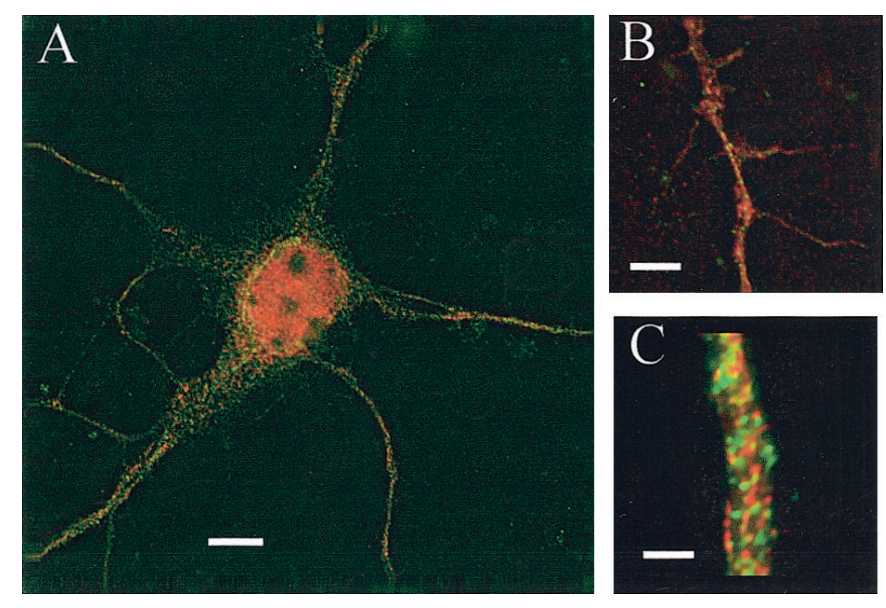

Figure 1. Immunostaining for the NR1 subunit of the NMDAR and MLCK demonstrates that MLCK is present in low-density cultures of mouse hippocampal neurons but does not colocalize with NMDARs. $A$, Example of a double-stained hippocampal neuron showing strong MLCK staining $(\mathrm{red})$ in the cytosol of the cell body and more punctate NMDAR labeling (green) in the cell dendrites. $B, C$, At higher magnifications, MLCK immunostaining was seen extensively through the shaft of dendrites, but it did not overlap significantly (yellow) with the presumed labeling of dendritic spines by the NR1 N-terminal antibody. Scale bars: $A, 5 \mu \mathrm{m} ; B, 2 \mu \mathrm{m} ; C, 0.2 \mu \mathrm{m}$.

scribed previously (Weber et al., 1999). ML-7, ML-9, and latrunculin B were purchased from Biomol. Other chemicals were products of Sigma.

Statistical analysis. Currents were expressed as the mean \pm SEM normalized to the control values before the application of drugs or to the amplitude just after the formation of the whole-cell configuration when appropriate. Values in parentheses refer to the number of different cells used in the statistical analysis. Statistical analyses were performed using either Student's $t$ test or two-way ANOVA.

\section{RESULTS}

\section{MLCK-mediated modulation of NMDAR function}

We first determined whether we could detect the presence of MLCK in our cultured hippocampal neurons. Low-density cultures were double-labeled using a rabbit polyclonal antibody against MLCK and probed with a secondary antibody conjugated to $\mathrm{Cy} 3$ (red fluorescence), as well as with a commercial mouse antibody raised against an epitope in the $\mathrm{N}$ terminus of the NR1 subunit and conjugated to FITC (green fluorescence). All functional NMDARs contain at least a single NR1 subunit, so this NR1 antibody should label all receptors. In low-power deconvolution images, strong MLCK staining was seen in the cell body, as well as in the dendrites (Fig. $1 A$ ). The fluorescence signal for the $\mathrm{NR} 1$ receptor was punctuate and pronounced in the dendrites and presumed regions of the dendritic spines. On closer examination of the dendrites, the MLCK signal was expressed almost continuously throughout the interior of the dendrites themselves, whereas the NR1 signal in the dendrites appeared to be much more punctuate (Fig. 1B). Using higher magnification, we also examined "clusters" of NMDA receptors located in the presumed spines of dendrites (Fig. 1C). These images were striking for their lack of overlap of NR1 and MLCK signals (little yellow fluorescence). These results suggest that, although MLCK is located near the base of spines, it is unlikely to be intimately associated with postsynaptic NMDARs. Attempts to coimmunoprecipitate NR1 and MLCK were also unsuccessful (data not shown), providing additional evidence that MLCK and NMDARs are unlikely to be found together in the PSD.
To determine whether MLCK activity modulates NMDAR function, we included in the recording pipette AV25, a MLCK synthetic inhibitory peptide based on the autoinhibitory domain of MLCK. This peptide has been shown to inhibit MLCK activity, as well as $\mathrm{Ca}^{2+}$-induced smooth muscle contraction (Weber et al., 1999). NMDA-evoked currents in acutely isolated CA1 pyramidal neurons are stable for a period of at least $30 \mathrm{~min}(\mathrm{Lu}$ et al., 1998) (Fig. 2A). However, these currents "ran down" when AV25 $(100 \mu \mathrm{M})$ was included in the recording pipette (Fig. 2A). Peak currents $\left(I_{\mathrm{p}}\right)$ were reduced to $65.7 \pm 2.8 \%(n=10)$ of the initial amplitude after $10 \mathrm{~min}$ of whole-cell recording in the presence of AV25, whereas these currents were unchanged in control recordings $(95.3 \pm 3.8 \% ; n=10 ; p<0.01)$. Steady-state currents $\left(I_{\mathrm{ss}}\right)$ appeared to be less sensitive to AV25 (Fig. 2A,B). Therefore, steady-state to peak current ratios $\left(I_{\mathrm{ss}} / I_{\mathrm{p}}\right)$ were enhanced by AV25 (Fig. 2B), suggesting that desensitization or inactivation of NMDAR-mediated currents had also been altered by AV25.

To further evaluate the involvement of MLCK activity, we studied the effect of the membrane-permeable MLCK inhibitor ML-7 on NMDAR function. Bath application of ML-7 (10 $\mu \mathrm{M})$ decreased $I_{\mathrm{ss}}$ and to a greater degree reduced $I_{\mathrm{p}}$ (Fig. 2C). After 4 min of application of ML-7, $I_{\mathrm{p}}$ and $I_{\mathrm{ss}}$ were depressed to $57.6 \pm$ 2.6 and $67.1 \pm 3.3 \%$ of their respective control values $(n=14$; $p<0.01$ ) (Fig. 2C,D). The ratio of $I_{\mathrm{ss}} / I_{\mathrm{p}}$ was therefore enhanced to $116.9 \pm 3.5 \%$ of the control $(n=14)$ (Fig. $2 D)$. ML-7 inhibited $I_{\mathrm{p}}$ with an $\mathrm{IC}_{50}$ of $3.4 \mu \mathrm{M}$ (Fig. $\left.3 A\right)$. ML-9 $(30 \mu \mathrm{M})$, another membrane-permeable MLCK inhibitor, inhibited $I_{\mathrm{p}}$ and $I_{\mathrm{ss}}$ by $36.5 \pm 4.3$ and $23.4 \pm 4.1 \%$, respectively, and enhanced $I_{\mathrm{ss}} / I_{\mathrm{p}}$ by $21.5 \pm 2.6 \%(n=8 ; p<0.01)$. The $\mathrm{IC}_{50}$ value of ML-9 for the inhibition of $I_{\mathrm{p}}$ was $7.7 \mu \mathrm{M}$ (Fig. $3 A$ ), which is similar to the $K_{\mathrm{i}}$ value $(3.8 \mu \mathrm{M})$ of ML-9-induced inhibition of purified MLCK and the $\mathrm{IC}_{50}$ value $(17.7 \mu \mathrm{M})$ of ML-9-induced inhibition of smooth muscle contraction (Saitoh et al., 1987; Ishikawa et al., 1988). This inhibition was not dependent on membrane potential (Fig. 3B), and these inhibitors did not alter the potencies of either NMDA (Fig. 3C) or its coagonist glycine (Fig. 3D).

AV25 and ML-7 (or ML-9) inhibit MLCK activity, but they do so by different mechanisms. Activation of MLCK occurs via a $\mathrm{Ca}^{2+}-\mathrm{CaM}$-induced conformational change that dissociates the autoinhibitory domain from the active catalytic site, thereby allowing access to its substrate myosin (Kamm and Stull, 2001). AV25 mimics the autoinhibitory domain by binding to the active site and preventing access of myosin to the catalytic site (Kamm and Stull, 2001), whereas ML-7 and ML-9 act by competing with ATP for binding to the kinase (Saitoh et al., 1987). We included AV25 in the recording pipette and then bath applied ML-7 to see whether AV25 would occlude the effects of this bath-applied inhibitor. We waited for $10 \mathrm{~min}$ after forming the whole-cell patch configuration to permit adequate entry of AV25 into the cell and to ensure maximal inhibition of endogenous MLCK activity. Subsequent bath application of ML-7 failed to further inhibit NMDAR-evoked currents $(92.3 \pm 4.3 \% ; n=8 ; p>0.05)$, indicating that both drugs likely act by inhibiting MLCK activity.

Given that NMDARs appear to be under the control of basal MLCK activity, we anticipated that application of exogenous MLCK might further potentiate NMDA-mediated currents, provided that the endogenous MLCK activity was not saturating for this response. We tested this possibility by including a constitutively active fragment of MLCK (61 kDa MLCK) in the recording pipette (Weber et al., 1999). Consistent with our expectations, intracellular perfusion of constitutively active MLCK (50 nM) 
A

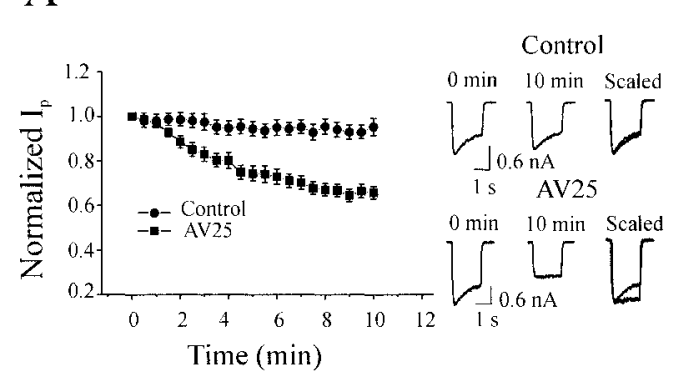

C

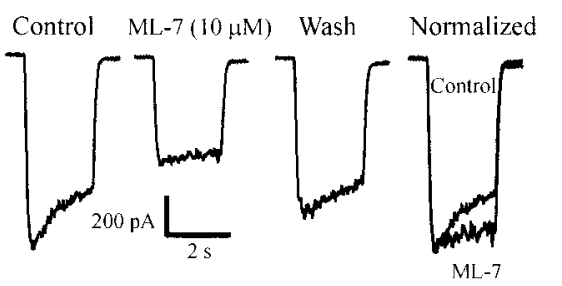

B
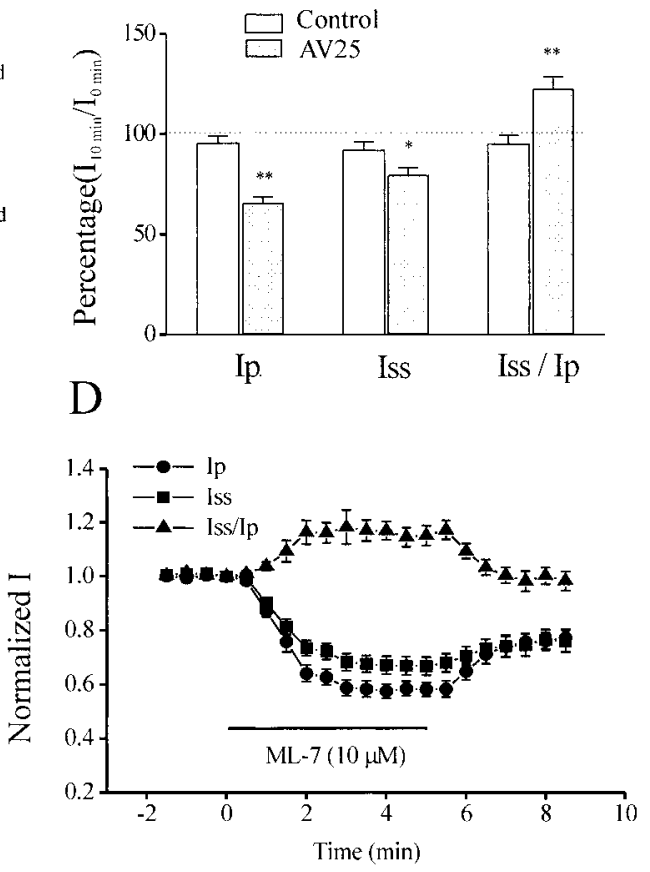

Figure 2. Modulation of NMDARmediated currents by inhibitors of MLCK activity. $A$, Time course of the inhibition of the peak $\left(I_{\mathrm{p}}\right)$ NMDAevoked currents after intracellular application of AV25 $(100 \mu \mathrm{M})$. Typical current traces from a control neuron (top) and a neuron perfused with AV25 (bottom) recorded immediately or $10 \mathrm{~min}$ after the formation of the whole-cell configuration are shown on the right. Note that the steady-state current $\left(I_{\mathrm{ss}}\right)$ was inhibited less than the peak current $\left(I_{\mathrm{p}}\right)$. $B$, Cumulative data $(n=10)$. Both $I_{\mathrm{p}}$ and $I_{\mathrm{ss}}$ were inhibited by the application of AV25 (via the recording pipette), but the ratio of $I_{\mathrm{ss}} / I_{\mathrm{p}}$ was enhanced because AV25 quantitatively affected $I_{\mathrm{p}}$ more than $I_{\mathrm{ss}}$. The ordinate gives the percentage of current at $10 \mathrm{~min}$ after whole-cell recording relative to that immediately after break in. $C$, NMDAR-mediated currents from a hippocampal CA1 neuron were inhibited by bath application of the membrane-permeable MLCK inhibitor ML-7. $D$, A plot of the time course of the effects of ML-7 on $I_{\mathrm{p}}, I_{\mathrm{ss}}$, and $I_{\mathrm{ss}} / I_{\mathrm{p}}(n=14)$. Note that ML-7 reduced $I_{\mathrm{p}}$ and $I_{\mathrm{ss}}$ but enhanced $I_{\mathrm{ss}} / I_{\mathrm{p}}$. increased NMDAR-mediated currents, whereas currents in control neurons (same buffer as the kinase) were unaltered (Fig. 3E). We also tested the specificity of AV25 and the constitutively active MLCK against NMDARs by examining their effects on AMPAR-mediated currents evoked by application of glutamate (1 $\mathrm{mM})$ in the presence of $\mathrm{Mg}^{2+}(3 \mathrm{mM})$ and AP-5 $(50 \mu \mathrm{M})$ to block NMDARs. Intracellular application of either AV25 or the MLCK (10 min) had no effect on AMPAR-mediated currents (Fig. 3F), demonstrating that MLCK specifically modulates NMDAR function.

\section{Modulation of NMDARs by MLCK is restricted to intact cells}

Our results suggest that MLCK may stimulate an actin-myosin interaction that then indirectly regulates the activity of NMDARs. We therefore investigated whether MLCK might regulate channel activity in the absence of the filamentous cytoskeleton. To achieve this, we applied AV25 or constitutively active MLCK directly to the cytoplasmic face of inside-out patches while simultaneously recording NMDAR single-channel activity. In this reduced preparation, the influence of the cytoskeleton should be eliminated or at least minimized. In these patches, application of the MLCK inhibitor AV25 (100 $\mu \mathrm{M})$ in the presence of $4 \mathrm{~mm}$ ATP failed to alter single-channel properties of NMDARs (Fig. 4A). Single-channel open probability, conductance, open times, and closed times were unaffected by the application of AV25 (Fig. 4F). One explanation for this negative result might be that endogenous MLCK was washed away from the membrane in the process of patch formation. If this were the case, then restoration of MLCK activity by exogenously applying constitutively active MLCK to the cytoplasmic face of the patch might be anticipated to enhance some aspect of single-channel properties. However, application of the constitutively active MLCK fragment (in the presence of ATP) did not change singlechannel properties (Fig. $4 B, F$ ), in contrast to our results with constitutively active MLCK in whole-cell recordings of NMDAevoked currents (Fig. 3E).
These results imply that the MLCK-mediated modulation of NMDARs requires an intact cytoskeleton, and, in the formation of an excised patch, the connection between MLCK and NMDARs was destroyed. We therefore investigated MLCK modulation of NMDAR channel activity in cell-attached patches, a configuration in which intracellular integrity is maintained. In this configuration, bath application of ML-7 (10 $\mu \mathrm{M})$ reduced the open probability of channels (Fig. $4 C, D$ ) without altering the channel conductance (Fig. $4 F$ ). Additional analysis indicated that ML-7 reduced the open time and increased closed times (Fig. $4 E, F)$. These results suggest that the action of MLCK is restricted to intact cells and perhaps requires a competent cytoskeleton.

\section{Actin-dependent modulation of NMDAR function by MLCK}

Because the intracellular C-terminal domains of NMDARs are linked to the actin cytoskeleton via $\alpha$-actinin (Wyszynski et al., 1997; Krupp et al., 1999) and spectrin (Wechsler and Teichberg, 1998), and the activity of MLCK modulates the interaction of actin and myosin, we next examined the potential requirement for filamentous actin of the MLCK-dependent regulation of NMDARs. We treated cultured hippocampal neurons with latrunculin B for $24 \mathrm{hr}$ to depolymerize actin and potentially disrupt the coupling of NMDARs to actin (Allison et al., 1998; Sattler et al., 1999). Recordings were made in the cell-attached patch configuration to minimally disrupt the intracellular milieu. In such recordings, NMDARs are protected from the bathapplied inhibitor ML-7, and, to modulate channel activity, the inhibitor must cross the membrane. Under these recording conditions in neurons pretreated with latrunculin B, ML-7 failed to inhibit NMDAR-mediated single-channel currents (Fig. 5C,D). This result demonstrates that the effects of ML-7 occur intracellularly and implies that intact actin filaments are required for the basal regulation of NMDARs by MLCK. To confirm that MLCK requires intact actin, we then tested the intracellular effects of AV25 and constitutively active MLCK on treated and untreated 
A

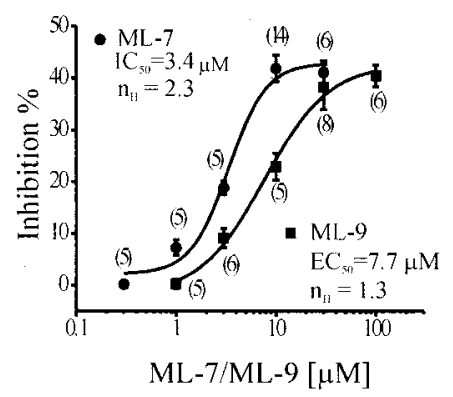

$\mathrm{C}$

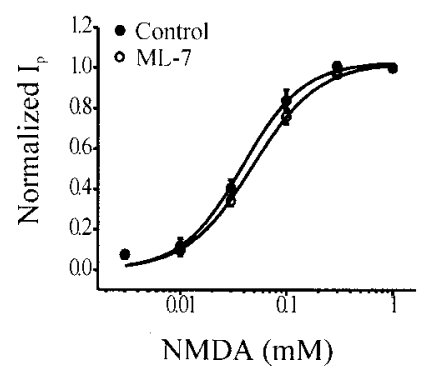

$\mathrm{B}$

$\mathrm{D}$

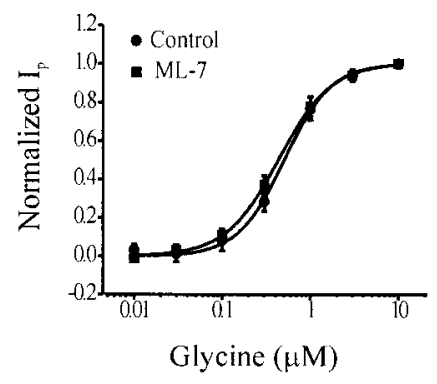

$\mathrm{E}$ Control MLCK
$0 \mathrm{~min} 10 \mathrm{~min}$
$0 \mathrm{~min} 10 \mathrm{~min}$

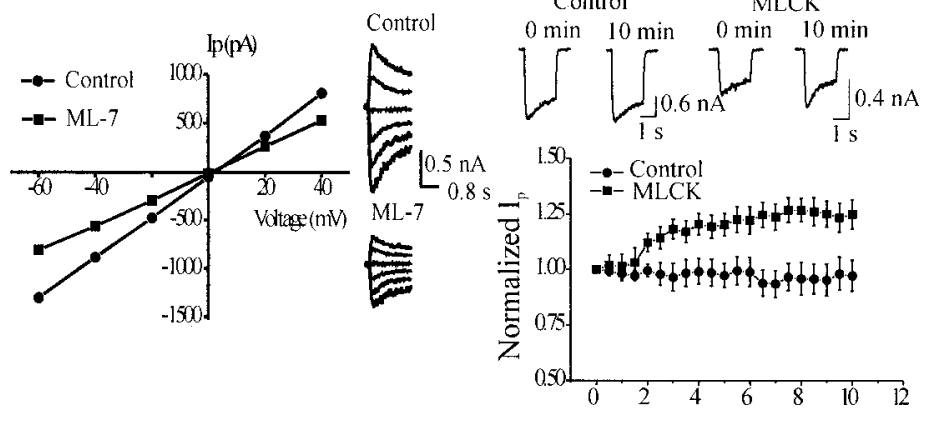

$\mathrm{F}$

Time (min)

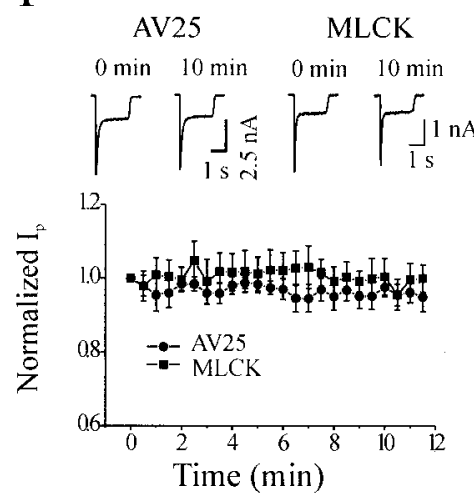

Figure 3. Properties of the inhibition by ML-7 and ML-9 and enhancement by exogenous MLCK of NMDA-evoked currents. $A$, Concentrationresponse curves for ML-7 and ML-9 for inhibition of $I_{\mathrm{p}}$. Numbers in parentheses denote the number of cells used. $B$, Inhibition of NMDAR currents is independent of membrane potential. Averaged currents from six neurons in the absence or presence of ML-7 at different holding potentials were plotted on the left, and on the right are the current traces before and during the application of ML-7 (10 $\mu \mathrm{M})$. $C, D$, The concentration-response curves for NMDA or glycine were not changed by application of ML-7 $(10 \mu \mathrm{M})$. NMDA: control, $\mathrm{EC}_{50}$ of $42.7 \pm 6.3 \mu \mathrm{M}, n_{\mathrm{H}}$ of $1.57 \pm 0.06 ; \mathrm{ML}^{-7}, \mathrm{EC}_{50}$ of $49.2 \pm$ $4.3 \mu \mathrm{M}, n_{\mathrm{H}}$ of $1.45 \pm 0.06 ; n=7 ; p>0.05$. Glycine: control, $\mathrm{EC}_{50}$ of $0.6 \pm 0.1 \mu \mathrm{M}, n_{\mathrm{H}}$ of $1.47 \pm 0.13 ; \mathrm{ML}^{-7,} \mathrm{EC}_{50}$ of $0.5 \pm 0.1 \mu \mathrm{M}, n_{\mathrm{H}}$ of $1.43 \pm 0.09$; $n=7 ; p>0.05$. E Intracellular application of constitutively active MLCK (50 nM) increased NMDAR currents. Shown in the top are current traces recorded immediately or $10 \mathrm{~min}$ after formation of the whole-cell configuration with or without MLCK in the recording pipette. Time courses of the effect of constitutively active MLCK are displayed in the bottom (control, $n=12$; MLCK, $n=14 ; p<0.001$ by two-way ANOVA). $F$, Lack of effect of AV25 $(100 \mu \mathrm{M} ; n=7)$ and MLCK $(50 \mathrm{nM} ; n=7)$ on AMPA receptor currents evoked by applications of L-glutamate $(1 \mathrm{mM})$ in the presence of $\mathrm{Mg}^{2+}(3 \mathrm{mM})$ and AP-5 $(50 \mu \mathrm{M})$. Current traces recorded immediately or $10 \mathrm{~min}$ after formation of whole-cell configuration from a neuron perfused with AV25 versus a neuron perfused with MLCK are shown at the top.

(control) cultured neurons. In contrast to control neurons, latrunculin B-treated neurons were insensitive to either AV25 or the constitutively active MLCK (Fig. $5 A, B)$.

\section{MLCK modulates rundown and $\mathrm{Ca}^{2+}$-dependent inactivation of NMDAR-mediated currents}

Actin is involved in at least two different aspects of NMDAR function. First, depolymerization of actin is thought to cause an irreversible and $\mathrm{Ca}^{2+}$-dependent rundown of NMDA-mediated currents in cultured neurons (Rosenmund and Westbrook, 1993a; Norenberg et al., 1999). Second, the influx of $\mathrm{Ca}^{2+}$ via NMDARs causes a transient and reversible inactivation of NMDA-evoked currents. This inactivation is triggered by $\mathrm{Ca}^{2+}$ and calmodulin and is mediated by their interactions with actin and $\alpha$-actinin (Ehlers et al., 1996; Krupp et al., 1999). We therefore tested potential relationships between these two phenomena and the effects of MLCK regulation of NMDARs. We used phalloidin, an actin-stabilizing agent that has been shown to inhibit the $\mathrm{Ca}^{2+}$ dependent rundown of NMDARs (Rosenmund and Westbrook, 1993a). If the actions of MLCK on NMDARs required the dynamic polymerization-depolymerization of actin, we anticipated that phalloidin might occlude or at least reduce the effect of
MLCK. Inclusion of phalloidin $(5 \mu \mathrm{M})$ in the pipette did indeed reduce the ML-7 (10 $\mu \mathrm{M})$-induced inhibition of NMDA-evoked currents (Fig. $6 A$ ).

We also examined responses to relatively low concentrations of agonist as a means of measuring the transient and $\mathrm{Ca}^{2+}$. dependent inactivation that occurs during the application of NMDA itself. Under these conditions, the decay of the current reflects only this $\mathrm{Ca}^{2+}$-dependent inactivation (Krupp et al., 1996). Bath application of ML-7 selectively depressed the initial peak current without changing the steady-state currents, and, as a consequence, the percentage of inactivation appeared to be reduced (Fig. 6B). This depression of the peak current suggests that ML-7 preinactivates currents and is consistent with a similar effect seen after the intracellular application of calmodulin or $\mathrm{Ca}^{2+}$ (Lu et al. 2000).

\section{Effect of MLCK on MEPSC $_{\text {NMDA }}$}

Because both actin and myosin are components of the PSD, a specialized structure restricted to the excitatory synapses (Walsh and Kuruc, 1992; Kennedy, 1997; Naisbitt et al., 2000), we also asked specifically whether synaptic NMDARs are regulated by MLCK in cultured hippocampal neurons. The role of MLCK in 
A

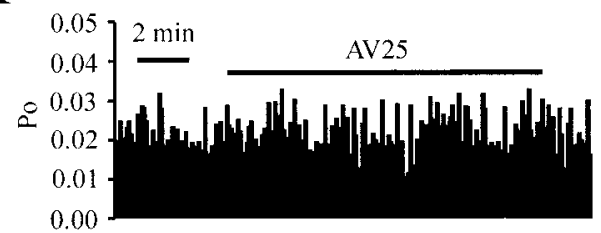

B
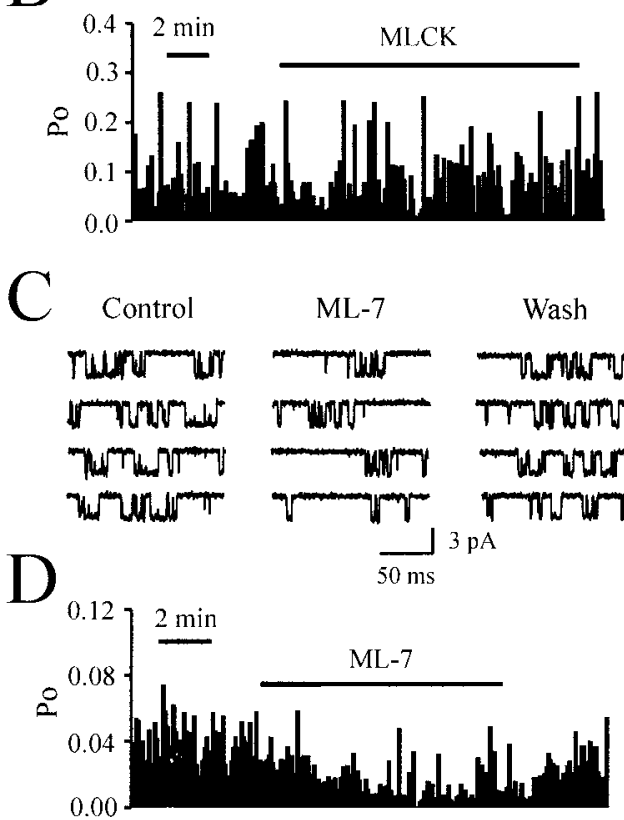

$\mathrm{E}$
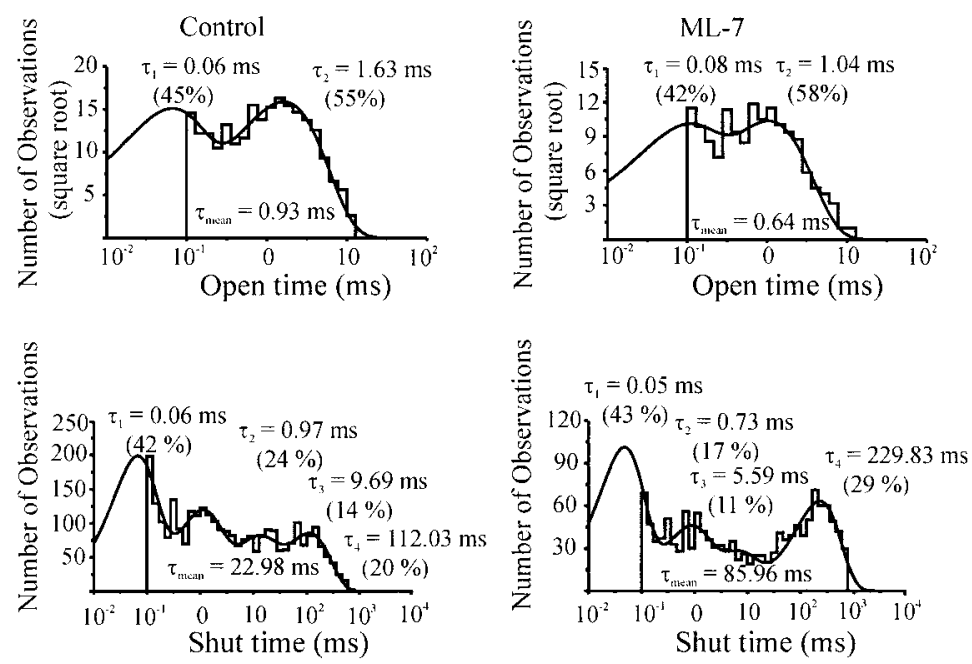

\section{$\mathrm{F}$}

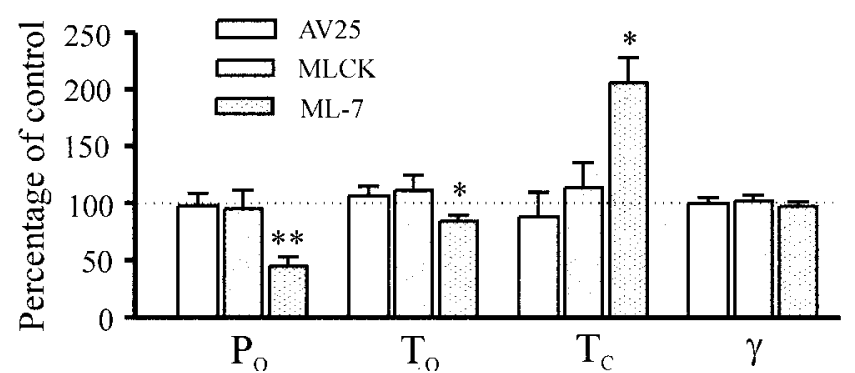

Figure 4. Effect of MLCK requires a competent cytoskeleton. $A$, A continuous record of NMDA single-channel open probability $\left(P_{\mathrm{O}}\right)$ before, during, and after application of AV25 $(100 \mu \mathrm{M})$ to the cytoplasmic face of an inside-out patch. NMDA single-channel $P_{\mathrm{O}}$ was calculated in bins of 5 sec duration. AV25 failed to modulate $P_{\mathrm{O}} . B$, Lack of effect of constitutively active MLCK applied to the cytoplasmic side on channel $P_{\mathrm{O}}$ in an inside-out patch. $C$, NMDA single-channel currents recorded in a cell-attached patch before, during, and after bath application of ML-7 (10 $\mu \mathrm{M})$. Note that ML-7 inhibited NMDA single-channel activity. $D$, A continuous recording of NMDA single-channel $P_{\mathrm{O}}$ before, during, and after application of ML-7 to the same patch as in $C$. Note that bath application of ML-7 reduced NMDA single-channel $P_{\mathrm{O}}$. E, Dwell-time histograms of open (top) and shut (bottom) times before (left) and during (right) bath application of ML-7. The time constant and the relative percentage of each component, as well as the weighted mean open and shut times, are displayed. Note that ML-7 reduced the mean open time but increased the shut time. F, Cumulative data for AV25, MLCK, and ML-7. Neither AV25 $\left(n=5\right.$ patches) nor MLCK $\left(n=6\right.$ patches) applied to the cytoplasmic face changed the open probability $\left(P_{\mathrm{O}}\right)$, mean open time $\left(T_{\mathrm{O}}\right)$, mean shut time $\left(T_{\mathrm{C}}\right)$, or conductance $(\gamma)$ of NMDA single-channel currents recorded in inside-out patches. ML-7 applied to the extracellular side reduced $P_{\mathrm{O}}$ and $T_{\mathrm{O}}$, increased $T_{\mathrm{C}}$, but failed to change $\gamma$ of NMDA single-channel currents recorded in cell-attached patches $(n=6$ patches).

regulating synaptic NMDARs was probed by including AV25 or constitutively active MLCK in the pipette while recording $\mathrm{MEP}$ $\mathrm{SC}_{\mathrm{NMDA}}$ (Fig. 6C). We compared the $\mathrm{mEPSC}_{\mathrm{NMDA}}$ recorded early $(<3 \mathrm{~min})$ and late $(>15 \mathrm{~min})$ after formation of the wholecell configuration. Inclusion of AV25 $(100 \mu \mathrm{M})$ in the pipette reduced the peak amplitude of the $\mathrm{mEPSC}_{\mathrm{NMDA}}$, whereas application of constitutively active MLCK (50 nM) enhanced these amplitudes without altering the AMPA component of mEPSCs (Fig. 6C-E).

\section{DISCUSSION}

We demonstrated that, in cultured and acutely isolated CA1 pyramidal neurons, NMDAR function is dependent on the activity of MLCK, as well as on the state of polymerization of filamentous actin. Using an antibody selective for MLCK, we showed that the enzyme is present in the dendrites of cultured hippocampal neurons but that it does not colocalize with NMDARs in dendritic spines. NMDAR-mediated whole-cell currents, which will activate both synaptic and extrasynaptic receptors, as well as mEPSC $_{\mathrm{NMDA}}$, were depressed by MLCK inhibitors (AV25 and ML-7) and enhanced by constitutively active MLCK. The naphthalene sulfonamide derivatives ML-7 and ML-9 inhibit MLCK as well as other kinases, including protein kinase $\mathrm{C}$ and $\mathrm{cAMP}$-dependent protein kinase, by competing with the ATP binding site of the kinase. However, in vitro, these inhibitors are approximately one order of magnitude more potent against MLCK than against PKC and PKA (Saitoh et al., 1986), and the $\mathrm{IC}_{50}$ values for ML-7 and ML-9 against NMDA-evoked currents were consistent with values for the selective inhibition of MLCK. Additional support for the block of endogenous MLCK was provided by our demonstration that the inhibitory peptide AV25, which mimics the autoinhibitory domain of MLCK (Weber et al., 1999), also caused a similar inhibition of NMDARmediated currents.

\section{Actin-dependent modulation of NMDAR function by MLCK}

Our results suggest that the MLCK-mediated modulation of NMDAR function is dependent on the integrity of the cytoskeleton because the autoinhibitory peptide AV25 and constitutively 
Figure 5. The effect of MLCK is dependent on the integrity of the actin cytoskeleton. $A$, A continuous record of $P_{\mathrm{O}}$ in a cell-attached patch from a neuron pretreated with latrunculin B before, during, and after the application of ML-7 (10 $\mu \mathrm{M})$ via the bath. Note that ML-7 failed to change $P_{\mathrm{O}}$ in this condition. $B$, Lack of effect of ML-7 on NMDA singlechannel properties of the neurons pretreated with latrunculin $\mathrm{B}(n=5$ patches). $C$, Current traces recorded from control neurons (left) or neurons pretreated with latrunculin B (right) with AV25 (top) or constitutively active MLCK (bottom). D, Lack of effect of AV25 or constitutively active MLCK in whole-cell recordings from neurons pretreated with latrunculin B. AV25 $(100 \mu \mathrm{M})$ or constitutively active MLCK (50 nM) was included in the recording pipette and currents at 10 $\min \left(I_{10} \mathrm{~min}\right)$ after formation of the whole-cell configuration were normalized to the currents recorded immediately after break in $\left(I_{0} \mathrm{~min}\right)$. Recordings were performed from cultured neurons pretreated with latrunculin $\mathrm{B}(5 \mu \mathrm{M})$ at $37^{\circ} \mathrm{C}$ or $0.1 \%$ DMSO (control).
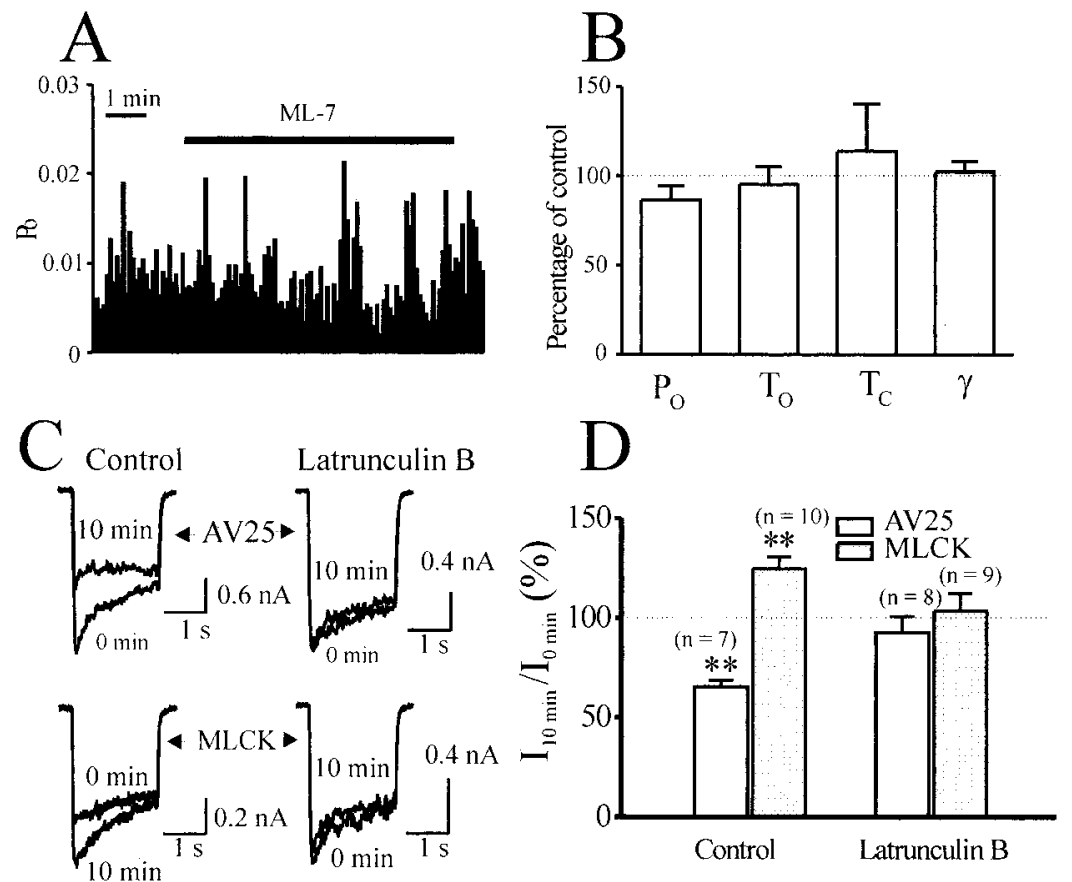
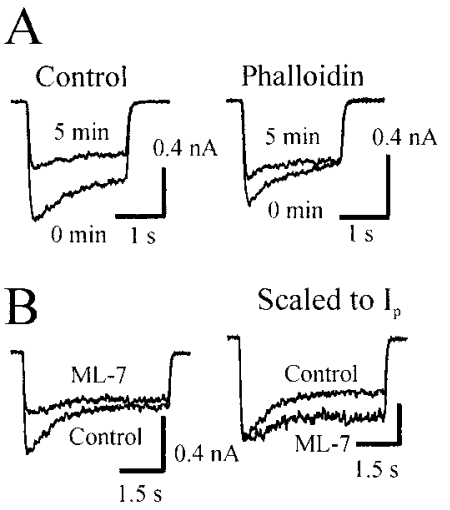

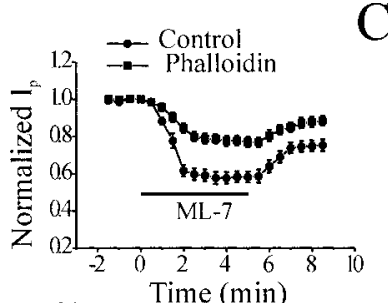

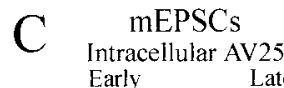

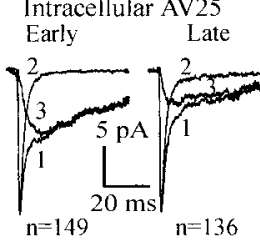

Intracellular MLCK

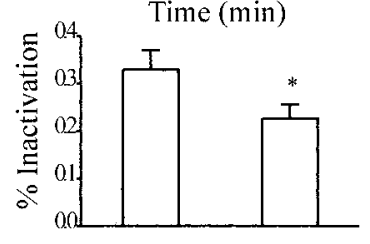

Control ML-7

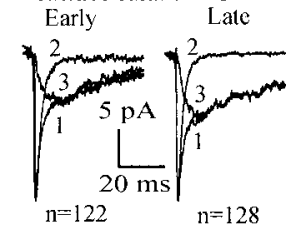

$\mathrm{D}$

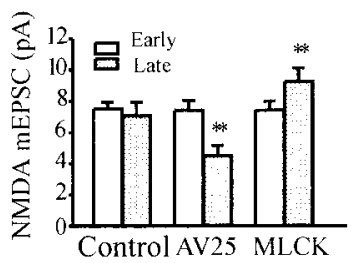

$\mathrm{E}$

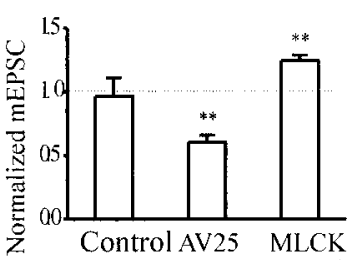

Figure 6. Modulation of rundown, $\mathrm{Ca}^{2+}$-dependent inactivation, and synaptic mEPSCs by MLCK. $A$, Inclusion of phalloidin (5 $\left.\mu \mathrm{M}\right)$ in the recording pipette reduced the inhibitory effect of ML-7 $(10 \mu \mathrm{M})$ on NMDAR currents (control, $n=12$; phalloidin, $n=15 ; p<0.001$ by two-way ANOVA). Current traces from a control neuron and a neuron perfused with phalloidin before and during the application of ML-7 are shown at the top. B, Bath application of ML-7 $(10 \mu \mathrm{M})$ enhanced the $\mathrm{Ca}^{2+}$-dependent inactivation of NMDA receptor currents. $\mathrm{Ca}^{2+}$-dependent inactivation was induced by application of NMDA $(20 \mu \mathrm{M})$ plus glycine $(10 \mu \mathrm{M})$ for $5 \mathrm{sec}$, and the extracellular $\mathrm{Ca}^{2+}$ concentration was increased to $1.8 \mathrm{~mm}$. Current traces from a neuron before and during the application of ML-7 are shown (left, unscaled; right, scaled). C, Intracellular application of AV25 (100 $\mu \mathrm{M}$; top) or constitutively active MLCK (50 nM; bottom) reduced or enhanced the amplitudes of mEPSCs of NMDA receptors, respectively. NMDA mEPSCs (denoted by 3 ) were isolated by subtracting AMPA components (denoted by 2) recorded in the presence of AP-5 (50 $\mu \mathrm{M})$, from the composite components (denoted by 1 ) in the absence of AP-5. Average NMDA mEPSCs recorded from the same neuron at early $(<3 \mathrm{~min})$ and late phases $(>15 \mathrm{~min})$. $D, E$, Cumulative data from control neurons $(n=5)$ and neurons perfused with $\operatorname{AV} 25(n=7)$ or constitutively active MLCK $(n=6)$. ${ }^{*} p<0.05$; ** $p<0.01$; paired $t$ test.

active MLCK were ineffective when applied to the cytoplasmic face of excised patches. In contrast, AV25, ML-7, ML-9, and constitutively active MLCK modulated NMDA-evoked wholecell currents, and bath application of ML-7 depressed the open probability of single-channel currents in cell-attached patches. Furthermore, both MLCK inhibitors and constitutively active MLCK were ineffective when applied to the neurons that were pretreated with latrunculin B to depolymerize filamentous actin. Our results are consistent with the observations that actin is bound to NMDARs via $\alpha$-actinin (Wyszynski et al., 1997; Krupp et al., 1999) and spectrin (Wechsler and Teichberg, 1998) and with the association of NMDARs and actin- $\alpha$-actinin with myo- sin of the PSD complex (Naisbitt et al., 2000). We suggest that MLCK activates myosin and causes physical tension to be transmitted via actin to the PSD and NMDARs. This model is consistent with observations that dendritic spines undergo continuous and actin-dependent submicrometer movements (Fischer et al., 1998). Furthermore, currents mediated by single NMDAR channels are sensitive to "stretch" or changes in membrane tension, and manipulations such as prolonged whole-cell patch clamp recording, which are likely to favor depolymerization of the cytoskeleton, sensitize NMDAR-mediated currents to stretch, suggesting that a stable cytoskeleton might also serve to stabilize NMDAR currents (Paoletti and Ascher, 1994). 


\section{MLCK: rundown and $\mathrm{Ca}^{2+}$-dependent inactivation of NMDARs}

In cultured neurons, a $\mathrm{Ca}^{2+}$-dependent and irreversible inhibition or rundown of NMDAR-mediated currents has been described in response to application of high concentrations of NMDA (Rosenmund and Westbrook, 1993b). This rundown of NMDA-evoked currents can be prevented by the actin stabilizing agent phalloidin or accelerated by cytochalasin D, suggesting that it results from depolymerization of filamentous actin (Rosenmund and Westbrook, 1993a,b). Our results in acutely isolated CA1 pyramidal neurons demonstrate that inhibitors of MLCK may cause a similar rundown of NMDA-evoked currents because phalloidin depressed the effect of the MLCK inhibitors, and depolymerization of the cytoskeleton with latrunculin B occluded the actions of the inhibitors. This conclusion is also supported by a recent study showing that the small GTPase RhoA plays a role in $\mathrm{Ca}^{2+}$-dependent rundown of NMDAR-mediated currents. Inhibition of RhoA, using C3 toxin, enhanced rundown of the currents in cultured cells (Norenberg et al., 1999). RhoA, acting via Rho-associated kinase, increases the phosphorylation of MLC by inhibiting the activity of myosin light chain phosphatase, which itself dephosphorylates MLC and opposes the actions of MLCK (Kimura et al., 1996; Maekawa et al., 1999; Sward et al., 2000). Inhibition of RhoA would in turn relieve the inhibition of myosin light chain phosphatase and decrease phosphorylation of MLC, leading to a rundown of NMDA currents. Our results are consistent with this scenario because NMDAR currents were reduced by MLCK inhibitors and enhanced by constitutively active MLCK.

Our results are also consistent with a potential role for MLCK in modulating the reversible and $\mathrm{Ca}^{2+}$-dependent inactivation of NMDAR-mediated currents. Inhibitors of MLCK occluded, and constitutively active MLCK enhanced, this inactivation. The MLCK-regulated tension or contractile activity expressed via actomyosin may modulate interactions between actin, $\alpha$-actinin, or spectrin and NMDARs.

The maintenance of a high density of neurotransmitter receptors at synapses involves binding of receptor subunits to a variety of scaffolding or anchoring proteins, which are in turn linked directly or indirectly to filamentous actin of the cytoskeleton. For example, nicotinic acetylcholine receptors at the neuromuscular junction are anchored to actin by association with rapsyn/43k and additional linker proteins (Carbonetto and Lindenbaum, 1995; Sanes, 1997), and glycine receptors at synapses of spinal cord neurons are linked to the microtubule-associated protein gephyrin as well as to actin-binding proteins such as profilin (Kneussel and Betz, 2000).

Postsynaptic AMPARs and NMDARs are also "clustered" at the subsynaptic membranes of excitatory synapses through their interactions with PSD proteins and linkages to the actin cytoskeleton. Relative to NMDARs, the number of AMPARs present at synapses is more dynamically regulated (Zhou et al., 2001), and changes in the number of these receptors can contribute to several forms of synaptic plasticity, including long-term potentiation (LTP) (Lledo et al., 1998; Shi et al., 1999; Hayashi et al., 2000; Lu et al., 2001) and long-term depression (LTD) (Luscher et al., 2000; Man et al., 2000; Turrigiano, 2000). At the excitatory synapses of CA1 pyramidal neurons, activation of NMDARs is required for the induction of both LTP and LTD (Malenka and Nicoll, 1999). NMDARs are more closely linked to the actin cytoskeleton, and the influx of $\mathrm{Ca}^{2+}$ via NMDARs can modify its interactions with actin binding proteins and actin, as well as potentially regulate depolymerization of the filamentous cytoskeleton (Van Rossum and Hanisch, 1999; Halpain, 2000; Jontes and Smith, 2000). Motility of dendritic spines has been implicated in the development of synapses, as well as potentially in the regulation of synapse size and number in the adult nervous system (Van Rossum and Hanisch, 1999; Halpain, 2000; Jontes and Smith, 2000). Our results suggest that NMDAR function is modulated through tension exerted by MLCK-dependent actinbased contraction or alternatively that contraction from a remotely located site modifies potential physical interactions between cytoskeletal proteins (i.e., $\alpha$-actinin and spectrin) and NMDARs. Actin may serve to dynamically position macromolecular signaling complexes and NMDARs within the spines during synaptic stimulation, and this type of mechanism might even contribute to short-term information storage at hippocampal synapses (Halpain, 2000).

\section{REFERENCES}

Allen BG, Walsh MP (1994) The biochemical basis of the regulation of smooth-muscle contraction. Trends Biochem Sci 19:362-368.

Allison DW, Gelfand VI, Spector I, Craig AM (1998) Role of actin in anchoring postsynaptic receptors in cultured hippocampal neurons: differential attachment of NMDA versus AMPA receptors. J Neurosci 18:2423-2436.

Carbonetto S, Lindenbaum M (1995) The basement membrane at the neuromuscular junction: a synaptic mediatrix. Curr Opin Neurobiol 5:596-605.

Ehlers MD, Zhang S, Bernhadt JP, Huganir RL (1996) Inactivation of NMDA receptors by direct interaction of calmodulin with the NR1 subunit. Cell 84:745-755.

Ehlers MD, Fung ET, O’Brien RJ, Huganir RL (1998) Splice variantspecific interaction of the NMDA receptor subunit NR1 with neuronal intermediate filaments. J Neurosci 18:720-730.

Fischer M, Kaech S, Knutti D, Matus A (1998) Rapid actin-based plasticity in dendritic spines. Neuron 20:847-854.

Fischer M, Kaech S, Wagner U, Brinkhaus H, Matus A (2000) Glutamate receptors regulate actin-based plasticity in dendritic spines. Nat Neurosci 3:887-894.

Halpain S (2000) Actin and the agile spine: how and why do dendritic spines dance? Trends Neurosci 23:141-146.

Hayashi Y, Shi SH, Esteban JA, Piccini A, Poncer JC, Malinow R (2000) Driving AMPA receptors into synapses by LTP and CaM KII: requirement for GluR1 and PDZ domain interaction. Science 287:2262-2267.

Husi H, Ward MA, Choudhary JS, Blackstock WP, Grant SG (2000) Proteomic analysis of NMDA receptor-adhesion protein signaling complexes. Nat Neurosci 3:661-669.

Ishikawa T, Chijiwa T, Hagiwara M, Mamiya S, Saitoh M, Hidaka H (1988) ML-9 inhibits the vascular contraction via the inhibition of myosin light chain phosphorylation. Mol Pharmacol 33:598-603.

Jian X, Szaro BG, Schmidt JT (1996) Myosin light chain kinase: expression in neurons and upregulation during axon regeneration. J Neurobiol 31:379-391.

Jontes JD, Smith SJ (2000) Filopodia, spines, and the generation of synaptic diversity. Neuron 27:11-14.

Kamm KE, Stull J T (2001) Dedicated myosin light chain kinases with diverse cellular functions. J Biol Chem 276:4527-4530.

Kennedy MB (1997) The postsynaptic density at glutamatergic synapses. Trends Neurosci 20:264-268.

Kimura K, Ito M, Amano M, Chihara K, Fukata Y, Nakafuku M, Yamamori B, Feng J, Nakano T, Okawa K, Iwamatsu A, Kaibuchi K (1996) Regulation of myosin phosphatase by Rho and Rho-associated kinase (Rho-kinase). Science 273:245-248.

Kneussel M, Betz H (2000) Clustering of inhibitory neurotransmitter receptors at developing postsynaptic sites: the membrane activation model. Trends Neurosci 23:429-435.

Krupp JJ, Vissel B, Heinemann SF, Westbrook GL (1996) Calciumdependent inactivation of recombinant $N$-methyl-D-aspartate receptors is NR2 subunit specific. Mol Pharmacol 50:1680-1688.

Krupp JJ, Vissel B, Thomas CG, Heinemann SF, Westbrook GL (1999) Interactions of calmodulin and alpha-actinin with the NR1 subunit modulate $\mathrm{Ca}^{2+}$-dependent inactivation of NMDA receptors. J Neurosci 19:1165-1178.

Legendre P, Rosenmund C, Westbrook GL (1993) Inactivation of NMDA channels in cultured hippocampal neurons by intracellular calcium. J Neurosci 13:674-684.

Lei S, Lu WY, Xiong ZG, Orser BA, Valenzuela CF, MacDonald JF (1999) Platelet-derived growth factor receptor-induced feed-forward 
inhibition of excitatory transmission between hippocampal pyramidal neurons. J Biol Chem 274:30617-30623.

Lledo PM, Zhang X, Sudhof TC, Malenka RC, Nicoll RA (1998) Postsynaptic membrane fusion and long-term potentiation. Science 279:399-403.

Lu WY, Xiong ZY, Orser BA, MacDonald J (1998) Multiple sites of action of neomycin, $\mathrm{Mg}^{2+}$ and spermine on the NMDA receptors of rat hippocampal CA pyramidal neurones. J Physiol (Lond) 512:29-46.

Lu WY, Jackson MF, Bai D, Orser BA, MacDonald JF (2000) In CA1 pyramidal neurons of the hippocampus protein kinase $\mathrm{C}$ regulates calcium-dependent inactivation of NMDA receptors. J Neurosci 20:4452-4461.

Lu W, Man H, Ju W, Trimble WS, MacDonald JF, Wang YT (2001) Activation of synaptic NMDA receptors induces membrane insertion of new AMPA receptors and LTP in cultured hippocampal neurons. Neuron 29:243-254.

Luscher C, Nicoll RA, Malenka RC, Muller D (2000) Synaptic plasticity and dynamic modulation of the postsynaptic membrane. Nat Neurosci 3:545-550

Maekawa M, Ishizaki T, Boku S, Watanabe N, Fujita A, Iwamatsu A, Obinata T, Ohashi K, Mizuno K, Narumiya S (1999) Signaling from Rho to the actin cytoskeleton through protein kinases ROCK and LIM-kinase. Science 285:895-898.

Malenka RC, Nicoll RA (1999) Long-term potentiation: a decade of progress? Science 285:1870-1874.

Man H-Y, Lin JW, Ju WH, Ahmadian G, Liu L, Becker LE, Sheng M, Wang YT (2000) Regulation of AMPA receptor-mediated synaptic transmission by clathrin-dependent receptor internalization. Neuron 25:649-662.

Matus A (2000) Actin-based plasticity in dendritic spines. Science 290:754-758

Matus A, Brinkhaus H, Wagner U (2000) Actin dynamics in dendritic spines: a form of regulated plasticity at excitatory synapses. Hippocampus 10:555-560.

Mochida S, Kobayashi H, Matsuda Y, Yuda Y, Muramoto K, Nonomura $\mathrm{Y}$ (1994) Myosin II is involved in transmitter release at synapses formed between rat sympathetic neurons in culture. Neuron 13:1131-1142.

Naisbitt S, Valtschanoff J, Allison DW, Sala C, Kim E, Craig AM, Weinberg RJ, Sheng M (2000) Interaction of the postsynaptic density95/guanylate kinase domain-associated protein complex with a light chain of myosin-V and dynein. J Neurosci 20:4524-4534.

Norenberg W, Hofmann F, Illes P, Aktories K, Meyer DK (1999) Rundown of somatodendritic $N$-methyl-D-aspartate (NMDA) receptor channels in rat hippocampal neurones: evidence for a role of the small GTPase RhoA. Br J Pharmacol 127:1060-1063.

Paoletti P, Ascher P (1994) Mechanosensitivity of NMDA receptors in cultured mouse central neurons. Neuron 13:645-655.

Paul ER, Ngai PK, Walsh MP, Groschel-Stewart U (1995) Embryonic chicken gizzard: expression of the smooth muscle regulatory proteins caldesmon and myosin light chain kinase. Cell Tissue Res 279:331-337.

Potier MC, Chelot E, Pekarsky Y, Gardiner K, Rossier J, Turnell WG (1995) The human myosin light chain kinase (MLCK) from hippocampus: cloning, sequencing, expression, and localization to 3qcen-q21. Genomics 29:562-570.

Rosenmund C, Westbrook GL (1993a) Calcium-induced actin depolymerization reduces NMDA channel activity. Neuron 10:805-814.

Rosenmund C, Westbrook GL (1993b) Rundown of $N$-methyl-Daspartate channels during whole-cell recording in rat hippocampal neurons: role of $\mathrm{Ca}^{2+}$ and ATP. J Physiol (Lond) 470:705-729.
Ruchhoeft ML, Harris WA (1997) Myosin functions in Xenopus retinal ganglion cell growth cone motility in vivo. J Neurobiol 32:567-578.

Ryan TA (1999) Inhibitors of myosin light chain kinase block synaptic vesicle pool mobilization during action potential firing. $\mathbf{J}$ Neurosci 19:1317-1323.

Saitoh M, Naka M, Hidaka H (1986) The modulatory role of myosin light chain phosphorylation in human platelet activation. Biochem Biophys Res Commun 140:280-287.

Saitoh M, Ishikawa T, Matsushima S, Naka M, Hidaka H (1987) Selective inhibition of catalytic activity of smooth muscle myosin light chain kinase. J Biol Chem 262:7796-7801.

Sanes JR (1997) Genetic analysis of postsynaptic differentiation at the vertebrate neuromuscular junction. Curr Opin Neurobiol 7:93-100.

Sattler R, Xiong Z, Lu WY, Hafner M, MacDonald JF, Tymianski M (1999) Specific coupling of NMDA receptor activation to nitric oxide neurotoxicity by PSD-95 protein. Science 284:1845-1848.

Sattler R, Xiong Z, Lu WY, MacDonald JF, Tymianski M (2000) Distinct roles of synaptic and extrasynaptic NMDA receptors in excitotoxicity. J Neurosci 20:22-33.

Sheng M, Pak DT (2000) Ligand-gated ion channel interactions with cytoskeletal and signaling proteins. Annu Rev Physiol 62:755-778.

Shi SH, Hayashi Y, Petralia RS, Zaman SH, Wenthold RJ, Svoboda K, Malinow R (1999) Rapid spine delivery and redistribution of AMPA receptors after synaptic NMDA receptor activation. Science 284:1811-1816.

Sward K, Dreja K, Susnjar M, Hellstrand P, Hartshorne DJ, Walsh MP (2000) Inhibition of Rho-associated kinase blocks agonist-induced $\mathrm{Ca}^{2+}$ sensitization of myosin phosphorylation and force in guinea-pig ileum. J Physiol (Lond) 522:33-49.

Turrigiano GG (2000) AMPA receptors unbound: membrane cycling and synaptic plasticity. Neuron 26:5-8.

Van Rossum D, Hanisch UK (1999) Cytoskeletal dynamics in dendritic spines: direct modulation by glutamate receptors? Trends Neurosci 22:290-295.

Van Rossum D, Kuhse J, Betz H (1999) Dynamic interaction between soluble tubulin and C-terminal domains of $N$-methyl-D-aspartate receptor subunits. J Neurochem 72:962-973.

Walsh MJ, Kuruc N (1992) The postsynaptic density: constituent and associated proteins characterized by electrophoresis, immunoblotting, and peptide sequencing. J Neurochem 59:667-678.

Wang LY, MacDonald JF (1995) Modulation by magnesium of the affinity of NMDA receptors for glycine in murine hippocampal neurones. J Physiol (Lond) 486:83-95.

Weber LP, Van Lierop JE, Walsh MP (1999) $\mathrm{Ca}^{2+}$-independent phosphorylation of myosin in rat caudal artery and chicken gizzard myofilaments. J Physiol (Lond) 516:805-824.

Wechsler A, Teichberg VI (1998) Brain spectrin binding to the NMDA receptor is regulated by phosphorylation, calcium and calmodulin. EMBO J 17:3931-3939.

Wyszynski M, Lin J, Rao A, Nigh E, Beggs AH, Craig AM, Sheng M (1997) Competitive binding of $\alpha$-actinin and calmodulin to the NMDA receptor. Nature 385:439-442.

Zhang S, Ehlers MD, Bernhardt JP, Su CT, Huganir RL (1998) Calmodulin mediates calcium-dependent inactivation of $N$-methyl-Daspartate receptors. Neuron 21:443-453.

Zhou Q, Xiao M, Nicoll RA (2001) Contribution of cytoskeleton to the internalization of AMPA receptors. Proc Natl Acad Sci USA 98:12611266. 